\title{
MARXISMO Y SOCIOLOGÍA ${ }^{1}$
}

\section{MARXISM AND SOCIOLOGY}

\author{
Henri Lefebvre ${ }^{2}$ \\ Traducción: Roy Alfaro Vargas*
}

RESUMEN

Lefebvre presenta en este artículo una reflexión alrededor del marxismo y de la definición que la sociología adquiere en su ligamen con el primero. Se explica además brevemente el método dialéctico, en cuanto fundamento del desarrollo de la sociología que permite unificar el rol de las ciencias sociales, en la comprensión de la totalidad (en este caso francesa). Asimismo, Lefebvre establece una serie de vínculos entre la Sociología y la Etnografía, la Economía Política, la Psicología y la Política, con el fin de aprehender las contradicciones que caracterizan la realidad social y fundar así una sociología científica.

PALABRAS CLAVE: CIENCIAS SOCIALES * INVESTIGACIÓN SOCIAL * FILOSOFÍA * DIALÉCTICA * MARXISMO

\section{ABSTRACT}

Lefebvre presents, in this article, a reflection around Marxism and the definition that the sociology acquires in relation to the former. Also it briefly explains the dialectical method, insofar as it is the basis for the development of a sociology that permits to unify the role of the social sciences in the comprehension of the totality (in this case, the French totality). In the same way, Lefebvre sets up an ensemble of links among the Sociology and the Ethnography, the Political Economy, the Psychology and the Politics, so as to apprehend the contradictions that characterizes the social reality and, thus, to establish a scientific sociology.

KEYWORDS: SOCIAL SCIENCES * SOCIAL RESEARCH * PHILOSOPHY * DIALECTICS * MARXISM

1 Traducido directamente del francés. El artículo original "Marxisme et Sociologie" apareció en los Cahiers Internationaux de Sociologie. Vol. 4, 1948: 48-74.

2 La visión lefebvriana de la sociología adquiere nuevamente valor dentro de un período donde hay en el mundo anglosajón y europeo una amplia difusión de la obra del intelectual francés, $y$ dentro de la actual crisis sistémica del capitalismo, con el evidente nuevo auge del marxismo, dentro del marco de una sociología que se ha antropologizado y fenomenologizado demasiado. Agradezco a mi amigo, Adrián Montero, por darme acceso al texto original de Lefebvre.

* Egresado del Posgrado en Literatura Latinoamericana de la Universidad de Costa Rica (UCR). royalfarov@gmail.com 
Un estudio detallado de los estudios de la Escuela sociológica francesa descubriría las profundas razones de sus debilidades, de su estancamiento, de su necesidad de renovación, que nadie hoy (parece) piensa negar.

Resumamos aquí brevemente las conclusiones de este análisis crítico, que desborda el marco de un simple artículo y que será efectuado en otro lugar.

1. La Escuela sociológica francesa no ha tenido una noción clara del "hecho sociológico". Ella ha oscilado y oscila todavía entre dos concepciones, una que representa el "hecho sociológico" como una cosa, pues como una entidad abstracta, metafísica, exterior a la actividad, a la voluntad $y$ asimismo, a la consciencia de los seres humanos (Durkheim), la otra que reduce los hechos sociales a unos hechos psicológicos individuales (la imitación de Tarde; la teoría "psicológica" del valor, aceptada por todos los economistas no-marxistas, etc.).

Estas dos concepciones tienen en común su idealismo. Aunque se tratase de "representaciones colectivas" o de "motivaciones individuales" - de un "ser social" o de una colección de consciencias individuales- el hecho sociológico $y$ humano se presenta como cortado de sus relaciones concretas con el poder del hombre sobre la naturaleza material, con las relaciones sociales prácticas de los seres humanos entre ellos.

2. Incapaz de asir los hechos sociales a la vez objetivamente (como realidades relativamente independiente de las opiniones e interpretaciones de los individuos en su propósito) y subjetivamente (en tanto, relaciones determinadas de los individuos en la condiciones históricas y sociales determinadas), esta sociología no ha podido definir un método verdaderamente científico. Ella oscila entre descripciones y clasificaciones (que solo son, como todos saben, un primer momento del conocimiento científico) y teorías explicativas abstractas, simplistas (en donde la teoría de la "mentalidad primitiva" resta el más célebre y más fastidioso ejemplo).

3. Esta escuela ha mostrado una tendencia, más que discutible,a buscar el hecho sociológico tan lejos como sea posible de lo actual, del presente - es decir, de lo concreto sociológico.

Ella se ha enredado en algunos problemas de origen. Se ha infinitamente preocupado más $y$ de mejor modo de los Aruntas o de los Bororos, que de la vida social real, cotidiana, en la cual estamos (antes de toda ideología) metidos.

Los marxistas estiman que solo el recurso al método marxista $y$ a las preocupaciones concretas del marxismo puede salvar la sociología francesa del estancamiento donde se encuentra $y$ devolverle la libertad en sus investigaciones, al tiempo que la fecundidad.

En este breve ensayo, se intentará primeramente recordar cómo Marx se ha servido del método dialéctico en el análisis de lo concreto sociológico; enseguida se ensayará trazar el plan de un verdadero instituto de las ciencias sociales, inspirado en un método dialéctico viviente, orientado hacia la comprensión de lo actual (de lo concreto sociológico).

\section{EL MÉTODO DIALÉCTICO EN LA SOCIOLOGÍA DE MARX}

Recordemos ante todo las características del método dialéctico.

Toda discusión, todo esfuerzo por avanzar en el conocimiento, proceden necesariamente por confrontación (diálogo) de tesis "opuestas" (el pro y el contra, el sí y el no, la afirmación y la negación). Esto es bastante conocido desde Platón para admitirlo sin dificultad.

Las contradicciones en el pensamiento humano (que se manifiestan en todas partes, a cada instante) plantean un problema esencial. Ellas tienen su origen, al menos parcialmente $y$ de vez en cuando, en las deficiencias del pensamiento humano que no puede asir, a la vez, todos los aspectos de una cosa $y$ debe romper (analizar) el conjunto para comprenderlo. Pero esta unilateralidad de todo pensamiento no basta; para explicar las contradicciones, es preciso admitir que en las cosas mismas estas contradicciones tienen un fundamento. Las contradicciones en el pensamiento $y$ la consciencia (subjetiva) de los hombres tienen pues un fundamento objetivo y real. Si hay un pro $y$ un contra, un "sí" y un "no", es porque las 
realidades tienen, no solamente varios aspectos, sino aspectos contradictorios. $\mathrm{Y}$ entonces el pensamiento del hombre que no llega a asir de golpe las cosas reales se encuentra obligado a tantear y a caminar a través de sus propias dificultades - sus contradicciones- para alcanzar las realidades y contradicciones reales.

De cara a este problema capital —planteado por las contradicciones - dos actitudes son posibles.

0 bien, uno rechaza en bloque, en lo absurdo, todas las contradicciones. Se decreta que estas son solo aparentes, superficiales; que ellas vienen únicamente de las flaquezas del pensamiento humano $y$ del hecho que no podemos aprehender de un salto, la verdad. Entonces, se supone necesariamente que esta verdad existe antes del esfuerzo humano por asirla, que el hombre podría o debería alcanzarla por "intuición" o "revelación" misteriosas, que esta verdad es eterna, inmóvil, inmutable. Esta es la actitud metafísica. Es claro que ella tiende a desatender $y$ al mismo tiempo a negar las condiciones concretas del esfuerzo humano por el conocimiento.

O bien, se admite, simultáneamente, que el pensamiento humano busca la verdad a través de las contradicciones y que las contradicciones tienen un sentido objetivo, un fundamento en lo real. Se cesa de rechazar en lo absurdo o en lo aparente toda contradicción; pero, al contrario, se coloca en el centro de las preocupaciones la búsqueda de las contradicciones $y$ de su fundamento objetivo. Se considera que los métodos tradicionales del pensamiento reflexivo deben ser profundizados en este sentido, determinando, más fuertemente que nunca, la verdad y la objetividad como objetivo de la razón, uno define una razón profundizada: la razón dialéctica.

Hoy, el problema es evidentemente fundamental. Él da lugar a un dilema, a un "o...o". Las dos respuestas son incompatibles. Para hablar propiamente, solo la razón dialéctica aporta una solución, ya que solo ella se esfuerza en comprender las contradicciones concretas de la investigación y las características concretas de lo real.

Marx ha primeramente adoptado $y$ empleado de manera coherente -en particular, en las cuestiones sociológicas- este método dialéctico elaborado especulativamente por Hegel. Metódicamente, estudiando una realidad objetiva determinada, analiza los aspectos y los elementos contradictorios de esta realidad (teniendo en cuenta, por consecuencia, todas las ideas contradictorias que tienen curso ante él, pero en las cuales no se sabía ver esto que contienen de verdadero). Después de haber distinguido estos aspectos o elementos contradictorios - sin desatender su lazo, sin olvidar que se trata de una realidadél reencuentra esto real en su unidad, es decir, en el conjunto de su movimiento.

Importantes indicaciones metodológicas se encuentran en el "Prefacio de El Capital". Un solo punto importa, escribe Marx: descubrir la ley de los fenómenos estudiados - descubrir no solamente la relación en un momento dado de los elementos del fenómeno, sino la ley de sus modificaciones $y$ de su evolución.

Para esto, es preciso distinguir el método de investigación y el método de exposición.

La investigación, insiste fuertemente Marx, debe "apropiarse en detalle" de la materia, del objeto estudiado; ella debe analizar y descubrir las relaciones internas de sus elementos. El método de análisis debe convenir al objeto estudiado; es preciso evitar emplear en economía política los métodos que permiten descubrir las leyes físicas o químicas. Más aún: cada período histórico posee sus propias leyes; el análisis de los hechos sociales muestra que entre los organismos sociales hay diferencias tan profundas como entre los organismos vegetales o animales, $y$ que el mismo fenómeno está sometido a leyes diferentes, siguiendo el conjunto en el cual figura.

Estudiar científicamente, analizar la vida económica, es pues descubrir en la formación económica y social un proceso natural, aunque sui generis, es decir, específico y diferente de los procesos físicos, químicos y biológicos. Es pues también descubrir las leyes particulares que rigen el nacimiento, el desarrollo y la muerte de cada conjunto social y su reemplazo por otro.

Después del análisis, viene la exposición. Cuando esta sale bien, la vida del objeto considerado, la materia estudiada, viene a expresarse 
en lo expuesto. A tal punto que los lectores se imaginan a veces tener ante ellos una construcción a priori de la cosa.

Descartes, en el Discurso del método, había ya dado algunas reglas para el análisis (alcanzar los elementos de la cosa estudiada) y la sintesis (reconstitución del conjunto).

Kant, Auguste Comte y desde luego otros, ya habían insistido sobre la exigencia fundamental de la investigación científica $y$ de la razón humana: no aislar el objeto considerado; buscar sus lazos, sus relaciones constantes $y$ regulares con otros fenómenos.

¿Qué aporta de nuevo el método marxista, inspirándose en Hegel, pero "poniendo sobre sus pies" la dialéctica todavía abstracta, metafísica, de esta filosofía?

a) Él afirma que el análisis, suficientemente profundizado, de toda realidad, alcanza los elementos contradictorios (por ejemplo: el proletariado y la burguesía).

Esta importancia de la contradicción había escapado, por razones históricas que uno podría investigar, a Descartes e igualmente, en gran parte a Kant (para no hablar de Auguste Comte). Solo Hegel la había percibido; enseguida Marx, aplicando la hipótesis hegeliana al análisis de la realidad social, económica y política, verifica la profunda verdad de ello: por tanto, de las contradicciones...

b) El método marxista insiste mucho más, particularmente, que las metodologías anteriores sobre un hecho esencial: la realidad por alcanzar mediante el análisis y por reconstituir mediante la exposición (sintética), es siempre una realidad en movimiento.

Aunque el análisis comience por romper este movimiento con el fin de alcanzar los elementos de este, y que también él llega a algunas abstracciones (como el biólogo que separa un tejido para estudiarlo o también una célula para examinarla al microscopio), el método marxista afirma que la reconstitución del todo y del movimiento es posible. Claramente, es preciso alcanzar por abstracción algunos "elementos" y para esto es necesario separarlos, aislarlos. Pero, cuando el análisis está bien conducido, solo separa los elementos para reencontrar las conexiones, las relaciones internas en el todo. Asimismo, él solo compara y solo descubre algunas analogías para discernir mejor las diferencias. Así, la reconstitución del conjunto, del todo en movimiento, no es incompatible con el análisis, con la disección anatómica de este todo. Al contrario...

c) Más particularmente que los métodos anteriores, el método marxista insiste sobre la originalidad (cualitativa) de cada especie de objetos estudiados y del mismo modo de cada objeto. Cada uno teniendo su cualidad, sus diferencias, el científico debe proponerse alcanzar la ley propia de este objeto: su devenir.

Pero, entonces, dirá uno, este método abandona todo principio universal, pues él cesa de ser racional: jél "se adapta" a cada objeto!

Nada de eso, si es verdad que el análisis se aplica a cada objeto "específicamente", entonces también aplica a él en todo caso, algunas verdades universales, tales como esta: "Por tanto, siempre, en toda cosa, hay contradicciones". Estas contradicciones pueden, en efecto, revelarse diferentes las unas de las otras, originales, "específicas" en cada caso; ellas no se ligan; sin embargo, a una teoría general, a una verdad universal, pues racional.

La aplicación a cada caso particular del método universal y racional no puede hacerse "mecánicamente". La teoría general de las contradicciones no permite decir cuáles contradicciones se encuentran en tal o cual objeto, en tal realidad particular, en el corazón de tal movimiento real. Nada remplaza el contacto con el objeto, su análisis, el embargo de su realidad, de su "materia".

Es así como el método dialéctico empleado por Marx difiere profundamente de la dialéctica hegeliana. ¿Qué hizo en efecto Hegel? Después de haber notado la importancia primordial de la contradicción en todos los dominios (naturaleza e historia), él ha creído poder definir abstractamente la contradicción en general, $y$ enseguida, se ha esforzado 
en servirse de esta definición lógica (formal) para reconstruir las contradicciones reales, los movimientos reales. Esta reconstrucción ( $y$ aunque Hegel tuviera en cuenta, de paso, muchos conocimientos adquiridos $y$ hechos concretos), solo tenía sentido en la cabeza del filósofo; era una reconstrucción especulativa - metafísica - de lo real. Todo lo que existe y vive, solo existe $y$ vive por un movimiento, un devenir; pero Hegel, a fuerza de abstracción, llegaba a una fórmula puramente abstracta, puramente lógica, del movimiento en general $y$ entonces se imaginaba tener en esta fórmula el método "absoluto", explicando toda cosa y escondiendo el movimiento de toda cosa.

Marx, al contrario ( $y$ no es preciso dejar de insistir sobre este punto esencial) afirma que la idea general -el método- no dispensa de asir en sí mismo cada objeto; él proporciona simplemente una guía, una orientación para la razón en el conocimiento de cada realidad. En cada realidad, es preciso asir sus contradicciones propias, $s u$ movimiento propio (interno), su cualidad y sus saltos cualitativos. La forma (lógica) del método debe pues subordinarse al contenido, al objeto, a la materia estudiada; él permite abordar el estudio de ello aprehendiendo el aspecto más general de esta realidad, pero no remplaza nunca la investigación científica por una construcción abstracta. De igual modo, si la exposición de los resultados obtenidos tiene el aire de una reconstrucción de la cosa, lo que no es más que una apariencia; no hay construcción o reconstrucción facticia, sino encadenamiento de los resultados de la investigación y del análisis, con el fin de reconstituir en su conjunto el movimiento (la historia) de la cosa; por ejemplo, la historia de El Capital.

Así, las ideas que uno se hace sobre las cosas - el mundo de las ideas - solo son el mundo real, material, expresado y reflexionado en la cabeza de los hombres.

¿Cuál será pues el método de la nueva ciencia que ha querido crear Marx: la Sociología científica?

Esta considera un conjunto, un todo concreto -tal país dado. Este conjunto concreto aparece enseguida bajo varios aspectos: población, repartición de la población en las ciudades y en las campiñas, producción y consumo, importación y exportación, etc. Una simple descripción, por ejemplo, del género de vida, de los trabajos o de la geografía humana, aporta ciertos conocimientos sociológicos sobre este país, pero no va muy lejos. Ella no muestra la historia de ello, la formación. Ella no alcanza la estructura económico-social, es decir, la esencia de los fenómenos que uno describe. Para profundizar, es preciso analizar.

¿Qué da el análisis? Él descubre enseguida grupos concretos de población (campesinos, obreros, artesanos; pequeños, medianos o grandes burgueses), es decir clases. Mas, estas clases solo son aún abstracciones si el análisis no se continúa y no alcanza los elementos sobre los cuales ellas reposan: el capital, el salario, etc. Pero estos, a su vez, suponen el intercambio, la división del trabajo, el precio, etc. El análisis muestra algunos elementos contradictorios e indisolubles (producción y consumo, conjunto social y clases sociales, etc.) y debe distinguirlos sin perder su vínculo. Además, él alcanza conceptos o categorías más y más simples, pero que están por así decir, comprometidas e incorporadas en la textura compleja de lo real social, que son pues los elementos reales: valor de uso $y$ valor de cambio, valores y precio, división del trabajo, etc.

Un cierto número de economistas y sociólogos se han espontáneamente comprometido con esta vía (desde Adam Smith hasta Durkheim; la división del trabajo ha sido a menudo estudiada). Pero, primeramente, no siendo dialécticos, pierden el vínculo de los elementos contradictorios; por ejemplo, estudian el consumo, la distribución de los productos (la circulación, el comercio, etc.) fuera de la producción, sin comprender que estos son dos aspectos inseparables del mismo proceso social, la producción siendo por otra parte el más esencial. O bien aún, no llegan a asir las relaciones entre la burguesía y el proletariado, relaciones dialécticas que envuelven un conflicto constante; estos dos aspectos reales de la sociedad moderna son nacidos simultáneamente y son inseparables, de tal suerte que los nodialécticos ven allá una simple simultaneidad 
o incluso, una armonía, aunque aquí, como en otros casos, la relación significa también: lucha, devenir, movimiento hacia una realidad nueva...

En segundo lugar, estos economistas y sociólogos, alcanzando algunos elementos simples (tales como, la división del trabajo, el valor de cambio y el valor de uso de los productos, etc.) solo ven aquí simples conceptos abstractos. Ellos detienen sus investigaciones en este resultado. No comprenden que este análisis solo era la primera parte de la investigación científica y que enseguida precisaba - sin arbitrariedad, sin reconstrucción fantasiosa de lo real- rehacer el camino en sentido contrario y reencontrar el todo, lo concreto, pero esta vez analizado y comprendido.

Esta exposición del todo concreto a partir de sus elementos, es según Marx, el único método científico. El primer método, el del análisis abstracto, desemboca en el "volatilizar" el todo concreto en conceptos por sí mismos, abstractos. Solo el segundo método permite reproducir lo real (su estructura y su movimiento) en el pensamiento. Sin embargo, este segundo método ofrece un riesgo, aquel mismo en el que cayó Hegel; este último comprendía muy bien que lo concreto es concreto, porque es complejo, rico en aspectos diversos, en determinaciones contradictorias y múltiples; de suerte que para el conocimiento, este concreto solo puede ser el resultado alcanzado por el análisis a través de él y después de él; esto aunque sea el verdadero punto de partida $y$ su conocimiento sea el objetivo del pensamiento. Pero Hegel creyó poder alcanzar este resultado por el solo pensamiento reflexionante aparte de sus propias fuerzas, por su solo movimiento. Al error del análisis abstracto corresponde el error de la síntesis abstracta en Hegel.

¿Cómo pues opera el método dialéctico? Él no toma abstractamente los elementos abstractos obtenidos mediante el análisis. Sabe que estos tienen, en tanto que elementos, un sentido concreto, una existencia concreta. Así, el análisis de El Capital alcanza un elemento simple entre todos: el valor (desde que hay intercambio, los productos toman un valor de cambio distinto del valor de uso). El método dialéctico reencuentra las condiciones concretas de esta simple determinación, en lugar de aislarla $y$ de considerarla separadamente; estas condiciones, tomadas en el movimiento real, son históricas. Así, el valor de cambio ha existido históricamente como "categoría" real $y$ dominante, en los inicios del capital comercial, en los "poros de la sociedad antigua" y en la Edad Media. En ese momento, en ciertas relaciones determinadas de producción (artesanal, por ejemplo), en un cierto tipo de comunidad, de familia $y$ de Estado, en tanto que aspecto esencial de un todo viviente, el valor de cambio apareció, no como concepto abstracto, sino como realidad concreta. En el curso del desarrollo histórico, el valor de cambio ha sido incorporado, envuelto en realidades $y$ determinaciones más complejas. En el capitalismo industrial y financiero, es solo una "categoría" elemental, implicada pero superada, modificada; él lleva aquí, en tanto que categoría económica, "una existencia antidiluviana". El análisis lo reencuentra bajo los sedimentos ulteriores, para emplear una metáfora fácil de comprender; lo reencuentra en el basamento económico-social actual, ya que sigue el movimiento histórico en el curso del cual la simple producción de mercancías y el valor de cambio como categoría dominante se han desarrollado, modificado, transformado en capitalismo, con sus leyes propias (formación de la ganancia y de la tasa de ganancia, etc.). El análisis permite así reencontrar el movimiento real en su conjunto, exponer y comprender la totalidad concreta actualmente dada, o sea, la estructura económico-social actual. El conocimiento de esa totalidad, a través de sus momentos históricos $y$ su devenir, es de hecho un resultado del pensamiento, pero no es para nada una reconstrucción abstracta obtenida por un pensamiento que acumularía algunos conceptos fuera de los hechos, de las experiencias, de los documentos.

\section{HACIA UNA SOCIOLOGÍA CONCRETA. PROYECTO DE UN PROGRAMA}

Dicho esto, es claro que la exposición de El Capital, dada por Marx, difiere notablemente del concreto sociológico al que nosotros hemos referido. 
Primeramente, lo real mismo, ha cambiado desde las investigaciones de Marx; nosotros asistimos a la decadencia, a la disolución, a la agonía convulsiva de este capitalismo, del cual él sigue su formación y del cual él solo pudo predecir a grandes líneas su destino.

En segundo lugar, porque entre el análisis de El Capital y la realidad dada (es decir, para nosotros la realidad francesa) subsiste una cierta diferencia. Concreto ya en un sentido y para su época, este análisis permanece abstracto en un sentido, en relación con esto que tenemos ante nuestros ojos. Resultado de un inmenso y genial esfuerzo científico, debió considerarse como instrumento, momento, etapa, para la comprensión y la explicación de lo concreto sociológico actual.

Los trabajos de un instituto moderno de Sociología científica podrían organizarse como sigue:

a) Solo tendría derecho al título de método propiamente dicho la dialéctica concreta; es decir, materialista, elaborado, confeccionado, verificado por Marx en El Capital.

Sin embargo, ninguna técnica de investigación sería rechazada. Estadísticas, encuestas, cuestionarios, entrevistas, descripciones, todos estos procedimientos de información pueden servir, cada uno en su espacio y lugar, en el marco de tal o cual problema planteado en función del método racional, sin que a cada técnica pueda atribuirse a una generalización abusiva. Asimismo, quizá precisará crear nuevos procedimientos investigativos adaptados para tal objetivo preciso ${ }^{3}$.

b) A la universalidad del método (dialéctico) debe corresponder el carácter preciso, concreto, del objeto de los estudios. El instituto de estudios sociológicos deberá proponerse como objetivo esencial la descripción,

3 Es así que M. Roger Veillé, jefe del servicio de contacto con los auditores de la radiodifusión, puso a punto una técnica de "muestreo" (sampling) por regiones francesas y de encuestas sobre la base común rural y del barrio urbano. la investigación "a profundidad", el inventario completo y la explicación de la realidad nacional actual.

La realidad francesa, en su totalidad $y$ en su devenir, tal es el objeto sociológico que, según el marxismo, solo puede abordarse científicamente con un método universal. La forma del pensamiento racional es universal, su contenido, su objeto, nacional.

c) En esto que concierne a la clasificación de las ciencias y a la clasificación general de los estudios, el nombre "Sociología científica" (para distinguirla de la Sociología especulativa de Durkheim, así como de las sociologías en apariencia positivas, de hecho abstractas y a menudo mistificantes) designará el conjunto de las ciencias sociales, racionalmente coordinadas por el empleo de un método universal. Se propone tachar la Sociología de la lista de las ciencias sociales particulares donde ella se encontraría al lado de la Economía Política, de la Historia, etc., en conflicto perpetuo con estas ciencias, por turno absorbidas por ella o absorbiéndolas.

¿Cuáles podrán ser estas ciencias sociales, en donde el conjunto orgánico constituirá la Sociología científica?

La Etnografía estudia las formaciones $y$ las estructuras sociales pre-capitalistas. Ella se ocupa pues de las sociedades llamadas "primitivas", formas de comunidad tales como la comunidad rural (campesina), de su descomposición, de las estructuras sociales de clase que se han erigido en el marco de tal comunidad y sobre ella (feudalismo en sus inicios al menos).

El dominio, muy vasto, de la Etnografía, se encuentra bastante bien definido. De un lado, se detiene en los inicios de la economía mercantil (del capital comercial); por consecuencia, el estudio de la ciudad griega o romana no pertenece más a la Etnografía.

Por otra parte, en la medida donde las formaciones precapitalistas subsisten o sobreviven en la época actual (en el campo francés, por ejemplo $y$ en los pueblos coloniales) el dominio 
de la Etnografía se extiende hasta la actualidad. En un sentido, por los remanentes sociales e ideológicos, vivimos aún en plena realidad etnográfica. Una gran parte de las costumbres, de los ritos usuales, de las acciones corrientes pone de pie la encuesta etnográfica (sin que esto implique, a priori, cualquier condena).

Es así que toman un sentido y su lugar, los trabajos de la escuela etnográfica moderna, en esto que concierne a Francia ${ }^{4}$.

A la Economía Política pertenece el estudio de las estructuras sociales capitalistas. Su dominio comprende pues toda la economía fundada sobre el intercambio; ninguna línea brutal la separa del dominio de la Etnografía. Sin embargo, desde la antigüedad, la estructura económico-social fundada sobre el intercambio de mercancías y el capital comercial naciente se distingue de las formaciones anteriores.

En el objeto de la Etnografía y el de la Economía Política existe una zona de transición y de influencia recíprocas que no implica ninguna confusión.

Del mismo modo, entre el reino de la Economía Política y la sociedad futura, en el cual habrán desaparecido la mercancía, el valor comercial y el dinero - o sea, la sociedad comunista-, debe encontrarse un período transicional, el período de la democracia socialista, lo que no implica ninguna confusión.

La Economía Política estudia las categorías económicas fundamentales: valor de cambio, mercancía, dinero, capital. Estudiando su desarrollo mediante el análisis teórico y con los hechos, ella es ya una ciencia histórica, sin suplantar la historia misma. El conocimiento de este desarrollo en su totalidad es indispensable para la comprensión de la estructura social actual (capitalismo en declive).

A la Historia pertenece el estudio de las instituciones, de los eventos, de los hombres, en el marco determinado de tal o cual estructura

4 Trabajos continuados por los equipos del Museo de Trocadero, animados por M.M. G-H. Rivière, Maget, etc. Citamos particularmente en lo que concierne al folklore, la estructura social, las tradiciones del Languedoc francés, los trabajos de M. René Nelli y del Instituto de Estudios Occitanés. social. Las categorías de la Economía Política determinan el momento histórico: por ejemplo, el siglo xvi está dominado por el capital comercial, el xviII, por el capital industrial y el xx, por el capital financiero. Este marco general $y$ sumario se ha encontrado colmado por innumerables actos humanos, los cuales estudia la Historia propiamente dicha. Ella debe llegar a seguir la formación de las formas de vida social, de las relaciones determinadas, de las instituciones, de los modos de actividad tales como: la religión, la moral, el derecho, el lenguaje, la educación y la cultura.

Aquí tienen su lugar la Psico-sociología y la Sociología propiamente dichas.

Siendo el individuo un hecho social, la Psicología entra parcialmente en la Sociología científica. Ella estudia en su movimiento (no fuera de la Historia) los modos de actividad y las estructuras de la conciencia individual. Así, la Edad Media, el Renacimiento, la época clásica, la Revolución, el romanticismo, el mundo moderno, tienen sus tipos de individualidades $y$ de relaciones individuales. Aquí, pero aquí solamente, encontrarían su lugar y su espacio las investigaciones "tipológicas", los estudios sobre la vida en interrelación ("microsociología" de M. Gurvitch, sin olvidar el hecho fundamental: estas relaciones no pueden separarse de una estructura económico-social, aunque ellas puedan reaccionar sobre ella).

La Psico-sociología se preocuparía de ciertos grupos que se mueven en general (pero no siempre) en la superficie de la realidad social, al nivel de las apariencias ideológicas, creando una mentalidad de grupo o de casta que deforma más o menos profundamente, la consciencia correcta (racional) de esta realidad.

Citemos desde ahora, como ejemplo, los intelectuales en general o los comediantes, los periodistas, los fabricantes de necesidades (publicistas, promotores de modelos, etc.).

La Política por último, no puede y no debe hallarse excluida de la Sociología científica o considerada como una parte vergonzosa. Arrebatada al empirismo, al "arte", al maquiavelismo, la política debe devenir una ciencia. Los sociólogos se han interrogado sin fin $y$ sin 
conclusión sobre las "aplicaciones" de la Sociología, sobre la experiencia y la experimentación sociológica. El momento ha llegado, parece, de considerar deliberadamente la Política como aplicación y experiencia sociológica. Los hombres políticos deben devenir los ingenieros de las fuerzas sociales. Un instituto de ciencias sociales debe pues comprender una sección política, estudiando bajo su diferentes aspectos la realidad actual y sus perspectivas, el Estado, el ciudadano (el hombre en tanto que ciudadano), la psicología política, la acción política.

Uno de los primeros esmeros del instituto de ciencias sociales sería estudiar en Francia, el aparato estatal, tal como funciona, tomando los textos oficiales y jurídicos, confrontándolos con la realidad.

Una historia objetiva y completa de este aparato estatal; tal como se ha constituido por superposiciones sucesivas después de Napoleón I, después de la monarquía, después de la Edad Media, sería de un interés y de una utilidad extremos.

Los diputados, los ministros pasan, las oficinas permanecen, tal es el axioma fundamental del poder real en Francia. iEsto comienza a saberse! Lo que uno conoce menos es la naturaleza, la estructura, el reclutamiento de estas "oficinas" que dominan la vida real del país.

¿Cuántos de los franceses saben que uno de los personajes más importantes, el más importante quizás, aunque poco visible y poco espectacular del país, es hoy el Director del Movimiento general del fondo?

En este dominio, talvez precisará disipar algunas ilusiones, debido a las pretensiones de las pretendidas aristocracias de técnicos, de "tecnócratas", ilusiones que parecen a veces compartidas asimismo por ciertas críticas de la "tecnocracia". Parece que la cuestión del aparato estatal pudiera considerarse separadamente. A pesar de ciertas apariencias, es decir, de ciertas pretensiones ideológicas y políticas de los "tecnócratas", el aparato del Estado no es quizá una clase autónoma luchando por su propia cuenta; al contrario, la lucha de clases, con todas sus dificultades, sus problemas, penetra hoy en el seno del Estado y de su aparato político-administrativo.
Y ha devenido una cuestión vital para la gente $y$ la nación en modificar este aparato, aligerarlo, simplificarlo, someterlo a las necesidades del pueblo y la nación, arrancarlo a la clase hasta aquí dominante que solo mantiene su dominación gracias a una máquina burocrática literalmente "secreta" según sus necesidades.

Marx ha dado sobre esta historia del Estado en general y más particularmente sobre la historia del Estado francés, algunas indicaciones importantes, que precisaría coordinar, prolongar y actualizar. Ha mostrado especialmente, cómo la burguesía francesa ha sacado provecho de todas las dificultades $y$ de todas las crisis para perfeccionar su dispositivo de gobierno $y$ de poder real, para seleccionar mejor su "personal".

Si la Sociología se ve actual y viva, ella no puede eludir estos hechos.

Todo observador imparcial y objetivo constata en este momento este esfuerzo obstinado, tenaz, de la clase hasta aquí dominante, para retomar en sus manos el aparato estatal, un instante comprometido y sacudido, para "modernizarlo" no en función de las auténticas exigencias de la vida moderna y de la vida del país, sino de sus propias exigencias, sin preocuparse de la contradicción entre estas dos órdenes de exigencias.

Un estudio objetivo reencontraría estas cuestiones abrasantes:

¿Cómo funcionan, oficialmente y de hecho, las Direcciones Generales de Movimiento de Fondos, del Presupuesto de la Caja de Depósitos y Consignaciones, el Banco dicho de Francia, etc.?

¿Cómo se contratan y funcionan la Inspección General de Finanzas y el Tribunal de Cuentas?

¿Cómo y por qué la Inspección de Finanzas ha creado junto a los diferentes servicios y departamentos ministeriales, algunos interventores dichos de Estado?

¿Cómo se reclutan y funcionan los diferentes "cuerpos" más o menos bien "constituidos"? (una encuesta sociológica, objetiva, dirigida en este sentido, donde la "constitución” remonta al Antiguo Régimen 
o igualmente a la Edad Media, como los mandatarios en los Mercados de París... ¿Una buena monografía sociológica de los Mercados Centrales no tendría más interés teórico y práctico que el estudio "sociométrico" de los "modelos culturales" en casa de tal o cual grupo facticio, sin que por otra parte, falte abandonar tales estudios? ¿No es una prueba de impotencia en el dominio del humanismo concreto $y$ de la Sociología, el abandono a favor de algunos reporteros ávidos de cosas pintorescas superficiales, de tantas realidades sociales complejas?).

Sería muy interesante y útil, la historia objetiva e imparcial de los Impuestos, que reuniría los documentos actualmente dispersados en la historia general, la historia del derecho, los manuales y cursos de derecho fiscal $y$ administrativo ${ }^{5}$...

Esto solo es un ejemplo, una sugestión, entre muchas otras...

Esto es más importante, si es posible...

A pesar de ciertos esfuerzos recientes $y$ meritorios, el inventario de los recursos económicos de Francia no ha sido nunca completamente efectuado.

En cuanto a su estructura social, esta permanece casi ignorada, dado el carácter incompleto, fragmentario, incierto de los documentos, de las estadísticas y de las obras. Ningún organismo, ningún instituto se ha propuesto hasta aquí, con un método objetivo y algunos medios suficientes, este inventario. ¿Por qué? Porque los poderes dichos "públicos" no tenían ningún interés en proponerlo y porque los intereses dichos "privados" se habrían más bien preocupado de velar por la verdad sociológica...

Esta necesidad de un "velo" se manifiesta en el lenguaje, en las maneras; deviene un curioso pudor. Las palabras "propietario" y "propiedad" han tomado algo de noble, de fuerte, de grande. Reflejan la autoridad del hombre que posee $y$ domina. Se habla con complacencia de "capitales". Pero la palabra "capitalista" permanece sospechosa, tiene un pequeño aspecto

$5 \quad$ Idea y proyecto de M. Henri Darciel, de Lyon. subversivo y pertenece al vocabulario de los especialistas - io de los revolucionarios! La buena sociedad no soporta el empleo de ella. Más de un economista "distinguido" hace parte de esta buena sociedad. Y sin demasiado asombro, pero no sin placer, uno encuentra en los tratados oficiales de economía política algunas frases como estas:

Lo que hace falta es un diccionario donde ciertas palabras serían desterradas. Uno abriría el diccionario en la letra C, la palabra capitalismo no figuraría en ninguna parte. La gente honesta tomaría el compromiso de honor de nunca emplearla. Estaría acuñada de prohibición y poco a poco caería en el desuso. ¡Qué reposo para el espíritu, qué claridad en el mundo! (Delhorbe, citado aprobatoriamente en Pirou y Byé, Tratado de economía política, p. 113).

¡He aquí donde llegan los sociólogos marxistas! ¿Es preciso asombrarse que los espíritus de los economistas, de los estadistas, de los sociólogos, de los juristas, de los historiadores se hayan desviado de lo concreto sociológico?

El capitalismo ha actuado profundamente sobre la estructura nacional; querer estudiarla evitando púdicamente toda alusión al capitalismo, a su historia, a sus exigencias, es una imposibilidad evidente.

Por lo demás, el "capitalismo" — se le ha ya notado arriba - solo es una categoría económico-social dominante, en sí misma aún abstracta.

De una parte, el capitalismo toma en Francia algunas formas originales, complejas $y$ variadas.

De otra parte, se une a otras formas económico-sociales anteriores, mismas muy complejas, donde unas sobreviven y se arrastran como consecuencia del capitalismo propiamente dicho, donde las otras son penetradas por él.

En el estudio del capitalismo en Francia, conviene pues en primer lugar, discernir sus formas, por ejemplo, el capitalismo de "superposición" (que agrupa respetando más o menos su autonomía, algunas empresas preexistentes $y$ les superpone una dirección central o una 
empresa más considerable que las "cubra") y el capitalismo "absorbente", aquel de las potentes empresas concentradas (uno encuentra sobre estos puntos muy buenas indicaciones, en la obra de P. George sobre la Géographie économique et sociale de la France -Geografía económica y social de Francia-, 1937, París). El primer trabajo sobre este punto, de un instituto de ciencias sociales, sería retomar y desarrollar estas investigaciones.

En esto que concierne a las estructuras sociales, sería urgente proceder a una vasta encuesta sobre la estructura agraria de Francia. Ella es poco conocida, los problema complejos que ella plantea lo son aún menos, solo los interesados, a escala local, tienen consciencia de ello. La menor investigación en este sentido revela primeramente, el carácter incompleto de los documentos - la ignorancia, la mala voluntad, la incompetencia, la parcialidad de ciertos "servicios públicos"...

Cuando Marx murió, él no había terminado el examen de las cuestiones relativas a la renta territorial, a la propiedad territorial, a la estructura agraria. Varios, entre los últimos capítulos de El Capital, les son consagrados; Engels nos enseña que después de 1870, Marx había comenzado algunos estudios especiales absolutamente nuevos sobre los problemas agrarios, a partir de documentos originales sobre Rusia.

En la infinita variedad de formas de la propiedad territorial tanto como de la explotación agrícola en Rusia, este país debía jugar, en el estudio de la renta territorial, el mismo rol que Inglaterra jugaba en el primer libro de El Capital, en el estudio del salario industrial. Desafortunadamente, Marx no pudo realizar este proyecto (Prólogo de Engels al tomo III de El Capital).

Es decir, precisaría retomar y aplicar a la campiña francesa las indicaciones esparcidas en El Capital, retomadas y ya organizadas en los últimos capítulos del tomo iII.

Una encuesta metódica, continuada por el instituto de ciencias sociales, permitiría levantar una cartografía de la campiña francesa primeramente, por regiones y seguida por su conjunto, discerniendo:

a) La propiedad territorial de origen feudal y precapitalista con sus modalidades de explotación (cultura intensiva, en técnicas inferiores - sistemas de parcelas, arrendamiento, regidores y criadosamos, etc.) - sin olvidar que esta propiedad territorial de origen precapitalista no permanece fuera del mercado, de las relaciones capitalistas, etc.

b) La pequeña propiedad campesina con su extrema variedad: obreros agrícolas poseyendo un trozo de terreno - semipropietarios y pequeños propietarios incapaces de bastarse, alquilando un suplemento de tierra o vendiendo su fuerza de trabajo como asalariados durante una parte del año- propiedad pequeña y mediana "independiente" o pretendidamente tal, con las variantes locales y regionales de su estructura, con las huellas y remanentes de la antigua comunidad rural, etc. (sin descuidar el hecho que la extensión de la propiedad no determina estrictamente su importancia).

c) La gran propiedad concentrada de tipo capitalista, cultivo intensivo, maquinaria $y$ técnicas superiores, asalariados agrícolas, su distribución, sus vínculos con el capitalismo industrial y financiero, etc. ${ }^{6}$ - sin descuidar el hecho que en ciertas regiones o ciertas culturas, una propiedad relativamente pequeña puede ser del tipo capitalista, que una tierra arrendada puede ser explotada según el tipo capitalista, etc.

La variedad de formas de la vida rural en Francia, le cede apenas a su diversidad en la antigua Rusia.

Se adivina el interés de esta cartografía detallada de la estructura social campesina para el estudio metódico de la productividad del suelo y de los productores, del movimiento de cooperativas agrícolas, etc.

6 Cfr. los notables estudios de A. Soboul en La Pensée. 
Salvo un imprevisto, este inventario económico y social del campesinado francés confirmaría los profundos análisis de Marx sobre el retraso de la producción agrícola en relación con la producción industrial.

Mas no se trata, en Francia, actualmente de otra cosa que de un simple retraso. Al envejecimiento del capitalismo industrial corresponde una verdadera degradación de la agricultura. En una tabla completa de la realidad francesa actual, esta degradación aparecería en toda su amplitud y esto en regiones enteras como el Suroeste.

Si la sociología oficial de la burguesía francesa ha hasta el presente, más bien evitado el estudio de las realidades sociales concretas, no es por falta de razones profundas. iEste examen manifestaría sus engaños y sus mistificaciones! ¿No sería este el balance de una quiebra, el de la burguesía?

El inventario de la realidad nacional no finalizaría con el estudio del capitalismo $y$ de las formaciones precapitalistas en la agricultura, la artesanía, etc. El análisis de los sectores de la producción (agrícola, artesanal, industrial en todos los grados de concentración del capital nacionalizado) no agota aún la realidad sociológica. No son los objetos de estudio los que faltan, ni los problemas, ellos se presentan por todas partes. La distribución igualmente, ameritaría una serie de monografías y un esfuerzo difícil de síntesis. Se reencontraría aquí la compleja cuestión de los intermediarios, de la estructura del capital comercial, de la función de estos intermediarios. Particularmente precisaría saber cómo y por qué la estructura de la producción agrícola y hortense en Francia, ha permitido el desarrollo de una enorme red de intermediarios $-y$ en qué medida se puede intervenir para modificar esta situación.

La estructura de las clases medias - los oficios femeninos tan poco conocidos objetivamente, etc.- propondrían a los autores de las monografías y de los cuestionarios, a los encuestadores, realidades complejas. Mencionemos de paso las investigaciones proseguidas, pero con poca objetividad y que habría tiempo de retomar, sobre los presupuestos familiares en las diferentes clases sociales, el empleo de la renta, etc. Los mismos comentarios para el sujeto de la demografía. Aquí, uno se aproxima a otro orden de fenómenos, aquellos que transcurren en la superficie de la realidad social, en el nivel de la "producción ideológica".

Este término de "producción ideológica" puede sorprender a aquellos que por hábito atribuyen el nacimiento de las ideas a funciones extrasociales, enteramente individuales (la razón, el pensamiento, la intención, etc.). Y sin embargo, el examen de los hechos (tomemos como ejemplo el periodismo o la edición) muestra incontestablemente que allá hay verdaderas funciones sociales, respondiendo a ciertas necesidades sociales, es decir, una producción, una "oferta" respondiendo a una "demanda" de tipo particular.

Estos fenómenos atañen a la Psicología social propiamente dicha.

A esta Psicología social o Psico-sociología pertenece el dominio casi íntegro de la antigua "sociología francesa": el estudio de las representaciones colectivas.

Las "representaciones colectivas" no se explican ni por las relaciones mecánicas de átomos sociales, ni por una entidad sociológica exterior a los individuos. Ellas se explican por las actividades de grupos sociales especializados, que tienen precisamente por función social producir representaciones, ideas (a veces verdaderas, a veces falsas) en un momento dado. Una verdadera Psicología social deberá pues primeramente, describir y definir estos grupos funcionales, $y$ también, los grupos para los cuales ellos funcionan y producen representaciones.

Algunas de las primeras cuestiones concretas que se plantean a la Psicología son estas: ¿qué es el público o la opinión pública?, ¿cuáles son los diferentes públicos actuales?, ¿aquel de los teatros, del cine, aquel que lea los semanarios, aquel que va a los cabarets, aquel que escucha la radio?, etc.

Es imposible estudiar la producción ideológica sin estudiar las necesidades, la "demanda social" en este dominio. El lazo del productor con el demandante es aquí de una especie particular: él se sitúa en el dominio de la consciencia y permanece por tanto, profundamente inconsciente. El escritor, por ejemplo, no conoce a aquellos para 
los cuales él escribe; él no comprende claramente sus necesidades, su expectativa, su "demanda". Sin embargo, él lo tiene en cuenta, salvo si es puramente lírico y subjetivo (incluso él busca una medida poética común a otros individuos). El escritor más personal busca su público, se hace su público, determina poco a poco los "vínculos" más o menos "comunes" que vuelven conmensurables con la consciencia de otros individuos su propia sensibilidad, sus temas, su lenguaje, etc.

Hay un dominio extremadamente vasto y sutil de adaptaciones recíprocas entre la "demanda social", la producción social y el esfuerzo de los individuos en el interior de un grupo funcional.

La Psicología social determinaría poco a poco, en sus funciones, sus formas de consciencia, sus condiciones de existencia, sus intereses, los grandes grupos funcionales y sus aspectos:

a) el grupo más general, el de los intelectuales, con sus numerosas diferenciaciones y subgrupos;

b) el grupo de los informadores (periodistas, columnistas de chismes, publicistas). ¿Cuál es la relación propia de este grupo con el público? ¿Qué se llama "actualidad"? ¿De dónde se saca la información y cómo se difunde?

c) el grupo de entretenimiento (artistas de variedades, de teatro, del cine, del cabaret, etc.) ¿Cuál es su público y su relación con este?

d) los grupos de fabricantes de necesidades (agentes de publicidad, modistos, modelistas, modelos, etc.) y sus proveedores de conductas (moralistas, cartománticos, predicadores y dirigentes de consciencias);

e) el grupo de los artistas propiamente dichos (pintores, escultores, etc.) donde las relaciones con el público están lejos de ser claras, cualquiera que sea el grado de su esoterismo y de su tecnicidad.

El aporte de una Psicología social bien hecha a otras ciencias, a otros dominios de investigación (como por ejemplo la estética) sería inapreciable. Ella y solo ella permitiría responder a ciertas cuestiones muy simples en apariencia (como estas: ¿qué es la vulgaridad?, ¿de dónde viene el gusto por la vulgaridad?, ¿el éxito de la vulgaridad?, ¿qué es el éxito?, etc.). La Psicología social, desde luego, no puede definir esto que es bello, interesante, agradable, etc., sino más bien en qué consiste la vulgaridad o incluso, cuáles necesidades sociales permiten la obra bella. Ella no puede explicar los "valores" duraderos, sino más bien los pseudo-valores transitorios.

Sea dicho de paso, el postulado de los Institutos Gallup y de las prospecciones puramente estadísticas sobre el público no es otra cosa que el postulado mecánico: el individuo —átomo social. Habría lugar para examinar atentamente los resultados de las encuestas Gallup y probablemente denunciar (en las cuestiones planteadas $y$ en materia de plantearlas) una mistificación: aquella de una propaganda que hábilmente se da por la expresión "objetiva" del "público".

En cuanto a las investigaciones sobre los "modelos culturales", seguidas igualmente en América, ellas se afanan precisamente en esto que se trata de comprender: las representaciones. Estas investigaciones permanecen en la superficie de la sociedad en lugar de penetrar bajo las apariencias ideológicas, en el proceso social de creación. El problema se encuentra, una vez más, invertido.

El estudio estadístico del "público" o el estudio de acciones conformes con un "modelo cultural" preexistentes solo pueden dar lugar algunas informaciones parciales, son técnicas de investigación, con alcance limitado y sobre los cuales es imposible construir una sociología.

El dominio de la Psicología social no puede limitarse al examen de las representaciones dichas "colectivas".

Tiene ella que abordar en detalle la vida cotidiana y responder a esta cuestión: ¿cómo viven los seres humanos, según los grupos naturales (niños, mujeres, jóvenes, adultos, ancianos) y las clases sociales? En esta vasta encuesta, las técnicas de la biografía personal $y$ del cuestionario encontrarían su campo de aplicación. La cuestión "¿cómo viven los individuos?" reserva el domino de la Psicología propiamente dicha (estructura de la consciencia individual) pero se plantea en estrecha correlación con la exploración de este dominio. 


\section{CONCLUSIONES}

Para la Sociología científica, es decir, según nosotros, marxistas, los hechos sociales no son ni entidades $y$ cosas escapando a la consciencia, ni estados subjetivos y psicológicos. Estos son relaciones entre humanos, relaciones prácticas, pues reales, sin tener la realidad de las cosas y sin ser extraños a la consciencia. Si ellos toman el aspecto de "cosas", hay ahí una apariencia, una ilusión. Tal es la noción fundamental permitiendo fundar por fin una "Sociología científica".

El programa de investigaciones sociológicas que se deduce de esta noción y del que se ha dado arriba un muy breve esbozo, da pie a múltiples objeciones, en tanto programa práctico.

Primeramente, supone una refundición de la enseñanza sociológica universitaria en Francia, así como de centros ya existentes de investigación, de estadística, etc.

Dados los obstáculos que reencuentra la más tímida tentativa de rejuvenecer los cuadros, en la enseñanza y en otras partes, se podrá juzgar quimérico tal programa. Y no se tendrá enteramente la razón, infelizmente...

Para realizarlo, igualmente en parte, algunos medios materiales considerables serían necesarios, que faltan y faltarán por largo tiempo aún quizás: medios financieros, instalaciones $y$ encuestadores calificados.
Otra objeción más grave quizá: en el momento donde se terminara este inventario de la realidad nacional, esta ya habría tal vez cambiado...

A la primera objeción, se puede responder que este "programa" solo es un conjunto de sugerencias, de comentarios. El se propone indicar los problemas, no resolverlos. Si él suscita críticas, nuevas sugerencias o asimismo, algunas tentativas (monografías, encuestas, etc.), no habrá faltado a su objetivo.

A la segunda objeción, es preciso responder que este carácter moviente pertenece a todas las cosas, que el conocimiento, cuando posee definitivamente su objeto, se ve siempre frustrado $y$ que precisa tomar su parte en ello -que si la realidad social cambia, es que ella vive y que por último, cuando ella cambia, es lo mismo con una cierta continuidad.

¿Cómo sería completamente vano el estudio de las tendencias de este movimiento?

Deseamos ver con mucha prisa este esbozo superado por los hechos, los eventos, el saber...

Toulouse

Fecha de ingreso: 03/01/2012 Fecha de aprobación: 22/08/2012 